\title{
Meta
}

Journal des traducteurs

Translators' Journal

\section{DUBÉ, Jacques (1989) : Lexique analogique, Ottawa, Centre d'édition du gouvernement du Canada, 257 p.}

\section{Geneviève Raymond}

Volume 36, numéro 4, décembre 1991

URI : https://id.erudit.org/iderudit/003917ar

DOI : https://doi.org/10.7202/003917ar

Aller au sommaire du numéro

Éditeur(s)

Les Presses de l'Université de Montréal

ISSN

0026-0452 (imprimé)

1492-1421 (numérique)

Découvrir la revue

Citer ce compte rendu

Raymond, G. (1991). Compte rendu de [DUBÉ, Jacques (1989) : Lexique analogique, Ottawa, Centre d'édition du gouvernement du Canada, 257 p.]

Meta, 36(4), 663-664. https://doi.org/10.7202/003917ar

Ce document est protégé par la loi sur le droit d'auteur. L'utilisation des services d'Érudit (y compris la reproduction) est assujettie à sa politique d'utilisation que vous pouvez consulter en ligne.

https://apropos.erudit.org/fr/usagers/politique-dutilisation/
Cet article est diffusé et préservé par Érudit.

Érudit est un consortium interuniversitaire sans but lucratif composé de l’Université de Montréal, l'Université Laval et l'Université du Québec à Montréal. Il a pour mission la promotion et la valorisation de la recherche. https://www.erudit.org/fr/ 
- DUBÉ, Jacques (1989): Lexique analogique, Ottawa, Centre d'édition du gouvernement du Canada, $257 \mathrm{p}$.

Ayant eu à résoudre maintes fois les mêmes difficultés, Jacques Dubé, qui travaille depuis dix-sept ans comme traducteur au Secrétariat d'État du Canada, a d'abord consigné le fruit de ses recherches dans un fichier, par la suite publié sous la forme du Lexique analogique.

Cet ouvrage, destiné aux praticiens, regroupe les termes anglais du langage administratif et propose, pour chacun d'entre eux, toute une série d'équivalents français. Au traducteur comme au rédacteur, il permet donc d'éliminer quantité de recherches et de gagner un temps précieux, sans perte de qualité ni défaut de précision.

Un index anglais permet de repérer rapidement le terme recherché. Les entrées en caractères gras sont traitées dans le lexique, tandis que les autres renvoient à des synonymes ou à des entrées analogues. L'index français, plus important, renvoie à l'index anglais. Dans le lexique proprement dit, chaque rubrique contient une liste souvent impressionnante de solutions (équivalents, notions analogues, sens courants d'un terme, connotations). Un point d'interrogation signale les emplois critiqués ou les équivalents douteux. Certaines rubriques comprennent également des citations, pour la plupart tirées 
de la Sélection hebdomadaire du journal Le Monde, où figurent des emplois qui ne sont pas officiellement passés dans la langue.

La portée de cet ouvrage dépasse le domaine administratif. En effet, quel traducteur ne s'est, tôt ou tard, longuement interrogé sur les multiples nuances d'un mot et sur la meilleure manière de le rendre en fonction du contexte? Qu'il s'agisse de termes comme corporate, facilities, low profile, major, ou pattern, le Lexique analogique propose un nombre imposant de possibilités, lesquelles se multiplient par le jeu des renvois.

Cependant, compte tenu des nombreuses manipulations que ce lexique est appelé à subir, il est regrettable que sa reliure soit si fragile. De plus, l'entrée traitée devrait figurer, en lieu et place du titre, au haut de chaque page.

Néanmoins, ces réserves ne diminuent en rien l'utilité ni la souplesse du Lexique analogique, ouvrage somme toute extrêmement précieux.

GENEVIÈVE RAYMOND 